\title{
Baseline Needs Assessment for Breast Cancer Awareness and Management among Paramedical Health Care Providers in Iraq
}

\author{
Nada A.S. Alwan', Wafa' M. Alattar', Nawar Al Mallah ${ }^{3}$, Thamira K. Hassoun ${ }^{4}$ \\ ${ }^{1}$ Professor of Pathology (MD, PhD), Founding Director, National Cancer Research Center / Baghdad University \\ ${ }^{2}$ Professor of Nursing (PhD), National Cancer Research Center / Baghdad University \\ ${ }^{3}$ Assist. Lecturer, National Cancer Research Center / Baghdad University \\ ${ }^{4}$ Researcher, (MB. ChB), National Cancer Research Center / Baghdad University
}

\begin{abstract}
Background: Breast cancer ranks the first malignancy among the Iraqi population since three decades. The reported gap in the knowledge regarding that disease emphasizes the necessity for practical policy decisions to elevate the level of awareness among the Iraqi women, who often rely on their primary health care providers to obtain adequate guidance. Objectives: To assess the baseline needs for breast cancer awareness among paramedical health care providers in Iraq through exploring the level of knowledge, beliefs and attitudes towards the practice and management of breast cancer. Methodology: One hundred paramedical health care providers including nurses, biologistsand laboratory technicians, working in different departments of the Medical City Teaching Hospital,were involved in the current study. Each was asked to complete a structured questionnaire format which was prepared to evaluate the level of knowledge and beliefs towards breast cancer and its risk factors (18 items), barriers to screening (16 items) and the attitudes regarding the practice and management of early detection (8 items). Results: The answers of the respondents regarding the knowledge on breast cancer and its risk factors were remarkably good; approximately $83 \%$ had a score of $70 \%$ and over. It was interesting to observe that 95\% expressed willingness to join our National Cancer Research Program and 97\% were interested to learn more about breast cancer. Nevertheless, their positive impact on the beliefs towards the management and barriers to early detection of breast cancer in Iraq was relatively fair. While $77 \%$ actively proposed instructing all patients on the technique of Breast Self-Examination, only $52 \%$ had positive attitudes regarding providing Clinical Breast Examination if the women have no complaints;over $60 \%$ believed that women generally refuse to expose their breasts to a male physician and less than $50 \%$ agreed on offering Ultrasound to all women presenting with breast pain. On the other hand, about $70 \%$ readily accepted screening mammography if there is any breast complaint, $86 \%$ emphasized that patients actually go for needle aspiration when prescribed by the specialistand $64 \%$ confirmed that all diagnosed casesin their practice are usually scheduled for operations by examining surgeons in the same hospital. Conclusion and Recommendations: Our findings reveal insufficient conformity in the attitudes towards the practice of breast cancer management among the general paramedical providers in spite of their acceptable level of awareness. Abiding to protocol guidelines,throughdirected interventions, is mandatory to ensure overcomingthe existing barriers and adopting a successful nationwide public health educationalprogram on breast cancer control.
\end{abstract}

Keywords: Assessment, breast cancer, awareness, management, paramedical health care providers, Iraq

\section{Introduction}

In Iraq, breast cancer ranks the first among the population accounting for about $19 \%$ of all newly diagnosed cancers and $34.4 \%$ of the registered female cancers with an incidence rate approximating 23/100,000 female population (1). The highest frequencies are often encountered among middle aged women who usually present at advanced stages $(2,3)$ reflecting the limited access to screening, diagnostic and treatment facilities accompanied by lack of awareness on the significance of cancer control among the population (4-7).

It has been documented that almost $20 \%$ of Iraqi women presenting with palpable breast lumps in a major hospital were diagnosed with cancer. Only $32 \%$ sought medical advice within the first month after detection although in $47 \%$ the disease was at advanced stages (2). Earlier studies from Iraq revealed that about $50 \%$ of the educated Iraqi women had low knowledge scores on breast cancer (6); theirawareness on the means of early detection of the disease and its risk factors were significantly associated with practicing BSE (8). Such gaps about the relative importance of breast cancer in the community emphasized the necessity for practical policy decisions to elevate the level of awareness among Iraqi women $(4,9,10)$.Accordingly, the Regional Breast Cancer Research Project was initiated to document the clinical characteristics and management outcomes of patients diagnosed with the disease;with an emphasis on promoting public awareness campaigns on the significance of controlling the disease (11).

In many settings, women rely on their primary health care providers to obtain adequate guidance on cancer management. Focusing on the health care system within the Eastern Mediterranean Region, it was noted that within hospital records of many countries, there is improper documentation on the putative risk factors for breast cancer and the clinical profile of patients with the disease (11). Studies in the literature displayed that adherence to the screening recommendation guidelines has been suboptimal among the practicing health care providers (12). The perceptions and attitudes varied according to the gender, specialty and family practices $(13,14)$; indicating a lack of 


\section{International Journal of Science and Research (IJSR) \\ ISSN (Online): 2319-7064}

Index Copernicus Value (2015): 78.96 | Impact Factor (2015): 6.391

conformity in breast cancer screening practices among providers in different geographical settings.

The main objective of this study isto assess the level of awareness,beliefs and attitudes towards the practice and management of breast cancer amonga sample of paramedical health care providers in Iraq.

\section{Methodology}

Study Design: Descriptive study.

Study Sample: One hundred paramedical health care providers who worked under direct supervision of senior medical specialists. Those included Nurse Practitioners (41), Biologists (27) Laboratory Technicians (32)from the various departments of the Medical City Teaching Hospital in Baghdad. Fifty-five percent of the respondents were females and $57 \%$ had experienced over 10 years ofpracticein the medical sector (Table 1). It was interesting to observe that 95\% expressed willingness to join our National Cancer Research Program and 97\% were interested to learn more about breast cancer.

Study Setting: Data were collected and analyzed, within the National Cancer Research Center of Baghdad University and the Oncology Teaching Hospital of the Medical City Hospital in Iraq, during the period from June 2015 till May 2016.

InstrumentConstruction: Respondents were asked to complete a comprehensive structured questionnaire format which was prepared to evaluate the level of knowledge and beliefs towards breast cancer and its risk factors (18 items), barriers to screening (16 items) and the attitudes regarding the practice of the early detection techniques ( 8 items) among the studied sample of the paramedical health care providers. The overall knowledge score was classified as Poor (<50), Just Passed (50-59), Fair (60-69), Good (70-79), Very Good (80-89) and Excellent (>90).

Data Collection: The investigators held a direct interview with each respondent to obtain the requested data utilizing the constructed questionnaire format and informed written consents.

Statistical Analysis: Data were analyzed through the application of statistical procedures using the statistical package for the Social Sciences (SPSS version 22).

\section{Results}

Table 1: Characteristics of the Respondents.

\begin{tabular}{|c|c|}
\hline Variables & $\begin{array}{c}\text { Frequency/ } \\
100\end{array}$ \\
\hline Profession & \\
\hline Nurse Practitioners & 41 \\
\hline Biologists & 27 \\
\hline Laboratory Technicians & 32 \\
\hline Gender & \\
\hline Male & 45 \\
\hline Female & 55 \\
\hline
\end{tabular}

\begin{tabular}{|l|c|}
\hline Number of years in medical practice & 43 \\
$1-10$ & 29 \\
$11-20$ & 19 \\
$21-30$ & 9 \\
$>30$ & \\
\hline Interest to learn more about Breast Cancer & \\
Yes & 97 \\
No & 3 \\
Uncertain & 0 \\
\hline Willingness to join our National Breast & \\
Cancer Research Program & 95 \\
Yes & 4 \\
No & 1 \\
Uncertain & $\mathbf{1 0 0}$ \\
\hline Total & \\
\hline
\end{tabular}

Table 2: Assessment of the level of knowledge on breast cancer and its risk factors

\begin{tabular}{|c|c|c|c|}
\hline Items & $\begin{array}{l}\text { Yes } \\
\text { F/100 }\end{array}$ & $\begin{array}{c}\text { No } \\
\text { F/10 } \\
0\end{array}$ & $\begin{array}{l}\text { Uncerta } \\
\text { in } \\
\mathrm{F} / 100\end{array}$ \\
\hline $\begin{array}{l}\text { 1) } \mathrm{BC} \text { is the most common cancer in } \\
\text { your country }\end{array}$ & 92 & 6 & 2 \\
\hline $\begin{array}{l}\text { 2) More than } 50 \% \text { of women diagnosed } \\
\text { with BC in your country present in } \\
\text { late stages (Stages } 2 \mathrm{~B}, 3 \text { and } 4 \text { )? } \\
\end{array}$ & 84 & 7 & 9 \\
\hline $\begin{array}{l}\text { 3) Early stage BC is curable in more } \\
\text { than } 85 \% \text { of patients? }\end{array}$ & 82 & 11 & 7 \\
\hline $\begin{array}{l}\text { 4) Mammography screening could } \\
\text { reduce mortality from BC in about } \\
30 \% \text { of females over } 50 \text { years } \\
\end{array}$ & 68 & 17 & 15 \\
\hline \begin{tabular}{|l|l|} 
5) Majority of BC could be readily \\
diagnosed by needle biopsy \\
techniques
\end{tabular} & 86 & 8 & 3 \\
\hline $\begin{array}{l}\text { 6) } \begin{array}{l}\text { BC is usually a disease of high } \\
\text { socio-economic background in our } \\
\text { country }\end{array} \\
\end{array}$ & 19 & 75 & 6 \\
\hline $\begin{array}{l}\text { 7) According to the Iraqi Cancer } \\
\text { Registry BC affects mainly females } \\
\text { over } 50 \text { years }\end{array}$ & 9 & 79 & 12 \\
\hline $\begin{array}{l}\text { 8) Multiple pregnancy is a known risk } \\
\text { factor for BC }\end{array}$ & 7 & 78 & 15 \\
\hline $\begin{array}{l}\text { 9) Early menopause is usually } \\
\text { protective against contacting BC }\end{array}$ & 77 & 11 & 12 \\
\hline $\begin{array}{l}\text { 10) BC could affect females in their } \\
\text { twenties }\end{array}$ & 78 & 15 & 7 \\
\hline $\begin{array}{l}\text { 11) Premenopausal obesity increases the } \\
\text { risk of BC }\end{array}$ & 65 & 29 & 6 \\
\hline $\begin{array}{l}\text { 12) It is not uncommon for BC to affect } \\
\text { men }\end{array}$ & 75 & 20 & 5 \\
\hline 13) Stages $3 \& 4$ BC are always fatal & 21 & 77 & 2 \\
\hline 14) BC could be contagious & 7 & 88 & 5 \\
\hline 15) BC can be curable & 79 & 12 & 9 \\
\hline $\begin{array}{l}\text { 16) Having a family history of breast } \\
\text { canceralways increase the risk }\end{array}$ & 93 & 7 & 0 \\
\hline $\begin{array}{l}\text { 17) Screening mammography allow } 60- \\
70 \% \text { of BC to be detected at stages } 0 \\
\text { or I }\end{array}$ & 68 & 25 & 7 \\
\hline $\begin{array}{l}\text { 18) Small BC detected by screening } \\
\text { mammography could be treated by } \\
\text { lumpectomy without removing the } \\
\text { whole breast }\end{array}$ & 86 & 12 & \\
\hline
\end{tabular}

The answers of the respondents regarding the knowledge on breast cancer and its risk factors were remarkably good; approximately $83 \%$ had a score of $70 \%$ and over, while $11.1 \%$ presented excellent responses (Tables 2 and 3). The 


\section{International Journal of Science and Research (IJSR) \\ ISSN (Online): 2319-7064 \\ Index Copernicus Value (2015): 78.96 | Impact Factor (2015): 6.391}

most confusing questions were those related to the significance of mammography in down staging and reducing the mortality from the disease and the effect of postmenopausal obesity on increasing the risk of breast cancer. .

Table 3: Knowledge Scores on the responses related to breast cancer and its risk factors

\begin{tabular}{|c|c|c|}
\hline Scores of Correct Answers & Frequency & $\%$ of Total \\
\hline$<50$ & 0 & 0 \\
\hline$(50-59)$ & 0 & 0 \\
\hline$(60-69)$ & 3 & 16.7 \\
\hline$(70-79)$ & 8 & 44.4 \\
\hline Very Good $(80-89)$ & 5 & 27.8 \\
\hline Excellent $>90$ & 2 & 11.1 \\
\hline Total & 18 & 100.0 \\
\hline
\end{tabular}

Table 4: Assessment of the level of Beliefs towards breast cancer management and the Barriers to early detection

\begin{tabular}{|c|c|c|c|c|}
\hline \multicolumn{2}{|r|}{ Items } & $\begin{array}{c}\text { Yes } \\
\text { F/100 }\end{array}$ & $\begin{array}{c}\text { No } \\
\text { F/100 } \\
\end{array}$ & $\begin{array}{c}\text { Uncertain } \\
\mathrm{F} / 100\end{array}$ \\
\hline & $\begin{array}{l}\text { Belief that early detection of BC } \\
\text { could significantly improve survival }\end{array}$ & 95 & 3 & 2 \\
\hline 2) & $\begin{array}{l}\text { Necessity to include CBE in the } \\
\text { routine clinical check -up of female } \\
\text { patients, even if they have no breast } \\
\text { complaint }\end{array}$ & 81 & 12 & 7 \\
\hline 3) & $\begin{array}{l}\text { Urgent need to educate the } \\
\text { community about risk factors of } \mathrm{BC}\end{array}$ & 98 & 1 & 1 \\
\hline 4) & $\begin{array}{l}\text { Educating men about BC could have } \\
\text { a positive impact on the breast } \\
\text { health care of their wives }\end{array}$ & 87 & 8 & 5 \\
\hline 5) & $\begin{array}{l}\text { Annual screening mammography } \\
\text { could lead to BC }\end{array}$ & 7 & 87 & 6 \\
\hline 6) & $\begin{array}{l}\text { Most women fear examination } \\
\text { because they think breast cancer is a } \\
\text { fatal disease }\end{array}$ & 90 & 7 & 3 \\
\hline 7) & $\begin{array}{l}\text { Some women could think that breast } \\
\text { examination is against cultural } \\
\text { beliefs }\end{array}$ & 23 & 69 & 8 \\
\hline
\end{tabular}

8) Women are embarrassed to talk about their breast health care

9) Women do not have enough family support

10) Women worry about being rejected by their husbands if a breast tumor is diagnosed

11) Women may think breast cancer will bring disgrace to their family

12) Not all women have access to care

13) Women cannot financially afford breast health care

14) Women may think that mammograms could cause cancer

15) Some women could think that a lump will go away by itself

16) Some still think that breast health care is against religious beliefs

Table 5: Score -related responses regarding Beliefs and Barriers to early detection and management of breast cancer

\begin{tabular}{|c|l|c|c|}
\hline \multicolumn{2}{|c|}{ Score of Correct Answers } & Frequency & \% of Total \\
\hline \multirow{4}{*}{} & Poor $<50$ & 0 & 0 \\
\cline { 2 - 4 } & Passed $(50-59)$ & 3 & 18.8 \\
\cline { 2 - 4 } & Fair $(60-69)$ & 4 & 25.0 \\
\cline { 2 - 4 } & Good $(70-79)$ & 1 & 6.3 \\
\cline { 2 - 4 } & Very Good $(80-89)$ & 5 & 31.3 \\
Excellent $(>90$ & 3 & 18.8 \\
\cline { 2 - 4 } & Total & 18 & 100.0 \\
\hline
\end{tabular}

The responses regarding the beliefs towards breast cancer and the barriers to screening and early detection were less satisfactory. Although there was no failure rate, however, merely $56.4 \%$ of the paramedical health care providers presented positive impact approaching $70 \%$ and over. Nevertheless, $18.8 \%$ yielded excellent replies (Tables 4 and $5)$. It was illustrated that a proportion of the respondents believed that some Iraqi patients still think that a breast lump could fade by itself (45\%), mammography could cause cancer $(55 \%)$ and that women might not be able to afford breast health care financially $(47 \%)$.

Table 6: Attitudes towards the Practice of early detection of breast cancer

\begin{tabular}{|c|c|c|c|c|c|c|}
\hline Items & $\begin{array}{l}\text { Always } \\
\text { F/100 }\end{array}$ & \begin{tabular}{l|l|} 
Often \\
F/100
\end{tabular} & $\begin{array}{l}\text { Sometimes } \\
\text { F /100 }\end{array}$ & $\begin{array}{l}\text { Rarely } \\
\text { F/100 }\end{array}$ & $\begin{array}{l}\text { Never } \\
\text { F /100 }\end{array}$ & $\begin{array}{l}\text { Uncertain } \\
\text { F/100 }\end{array}$ \\
\hline $\begin{array}{l}\text { 1) } \mathrm{CBE}^{*} \text { is practiced in the routine clinical check-up of female patients, even } \\
\text { if they have no breast complaints }\end{array}$ & 30 & 22 & 27 & 5 & 6 & 10 \\
\hline $\begin{array}{l}\text { 2) Women generally accept CBE during routine clinical check-up, even if } \\
\text { they have no breast complaints }\end{array}$ & 34 & 24 & 29 & 8 & 2 & 3 \\
\hline 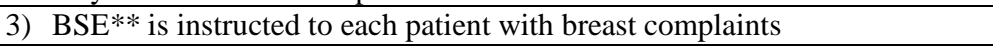 & 55 & 22 & 15 & 4 & 0 & 4 \\
\hline $\begin{array}{l}\text { 4) Breast Ultrasound screening is offered to all patients if they have only } \\
\text { breast pain. }\end{array}$ & 22 & 24 & 29 & 12 & 0 & 13 \\
\hline $\begin{array}{l}\text { 5) Women readily accept screening mammography if they have breast } \\
\text { complaints. }\end{array}$ & 36 & 33 & 10 & 5 & 0 & 16 \\
\hline $\begin{array}{l}\text { 6) All patients readily go for fine needle aspiration if they are instructed by } \\
\text { their surgeons. }\end{array}$ & 33 & 53 & 9 & 2 & 0 & 3 \\
\hline 7) Women generally refuse to examine their breasts by a male surgeon. & 19 & 42 & 32 & 7 & 0 & 0 \\
\hline 8) Patients diagnosed by BC are scheduled for operation in the same hospital. & 25 & 39 & 28 & 2 & 0 & 6 \\
\hline
\end{tabular}

*CBE: Clinical Breast Examination

**BSE: Breast Self-Examination

Table (6) presents the recorded attitudes towards practicing the early detection techniques and abiding to the protocol guidelines. While $77 \%$ actively proposed instructing all patients on the technique of Breast Self-Examination, only $52 \%$ had positive attitudes regarding providing Clinical
Breast Examination if the women have no complaints; over $60 \%$ believed that women generally refuse to expose their breasts to a male physician and less than $50 \%$ agreed on offering Ultrasound to all women presenting with breast pain. On the other hand, about $70 \%$ readily accepted

\section{Volume 6 Issue 7, July 2017 www.ijsr.net}




\section{International Journal of Science and Research (IJSR) \\ ISSN (Online): 2319-7064}

Index Copernicus Value (2015): 78.96 | Impact Factor (2015): 6.391

screening mammography if there is any breast complaint, $86 \%$ emphasized that patients actually go for needle aspiration when prescribed by the specialist and $64 \%$ confirmed that usually all diagnosed cases in their practice are scheduled for operations by examining surgeons in the same hospital.

\section{Discussion}

In spite of the improvement in survival from breast cancer in high-resource settings, the risk continues to increase among women in middle- and low-income countries $(15,16)$. In Iraq, breast cancer has become a major threat to femalehealth, being the leading causeof death after cardiovascular diseases amongwomen, forming a cancerrelated mortality rate of $23 \%(1,17)$. Having concluded that breast cancer is among the most common cancers amenable to early detection, WHO emphasized that strengthening screening and early detection are urgently recommended in the Eastern Mediterranean Region (EMR) to be built on the best international evidence and existing regional experience; taking into consideration the available resources, existing challenges and opportunities within the target population (18).

It was interesting to notice that the majority of the recruited sample in the study was willing to learn more about breast cancer and to join the activities of our National Cancer Research Program (97\% and 95\% respectively). In fact, the answers of the respondents regarding the knowledge on breast cancer and its risk factors were encouragingly good ( $83 \%$ had a score of $70 \%$ and over). The most confusing questions were those related to the hormonal related effects on the risk of breast cancer and the documented significance of mammography in down staging the disease and reducingits mortality.However, the responses regarding the beliefs towards the management of breast cancer and the barriers to early detection were less satisfactory, although $18.8 \%$ presented excellent scores. It was illustrated that a proportion of the paramedical health care providers believed that some patients still think that a breast lump could fade by itself (45\%), mammography could cause cancer (55\%) and that women might not be able to afford breast health care financially $(47 \%)$.

Previous studies reported knowledge gaps regarding the topic of breast cancer and its control amongthe Iraqi population in general $(5,6,8,19)$. The lack of well-designed diagnostic policies urgently necessitates the adoption of practical policy decisions to promote the abidance to a comprehensive breast cancer control strategy focusing primarily upon early detection through elevating the level of awareness among the Iraqi community (2-4, 9-11,20).In an earlier survey to determine the effects of peer education about breast cancer among female universities students in Baghdad, utilizing a pre and post-test educational model design, wedemonstrated a significant rise in the level of knowledge after the intervention (19).

On evaluating the attitudes towards practicing the early detection techniques according to protocol guidelines in this study,our findings revealed that $77 \%$ of the respondents proposed instructing all patients on the procedure of
BSEwhile only $52 \%$ had positive attitudes regarding providing $\mathrm{CBE}$ if the women have no complaints. Although more than $60 \%$ believed that women generally refuse to expose their breasts to a male physician, about $70 \%$ readily accepted screening mammography if there is any breast complaint and $86 \%$ emphasized that patients actually go for needle aspiration when prescribed by the specialist. In a recent case control study, that we carried out to compare the responses of a group of Iraqi female patients affected with breast cancer to a randomly selected group of apparently healthy women, it was found that the attitudes in both were relatively good with respect to seeking medical advice, accepting CBE, having the desire to be instructed on the technique of BSE and to undergo mammographic and fine needle biopsy examinations when requested (6).

In one of the studies that recruited primary care physicians it was reported that in spite of the fact that agreement with the National Cancer Institute and the American Cancer Society screening recommendations was high, for both CBE and mammography, practical adherence to those guidelines were suboptimal among providers (12). Another survey among primary care specialists in Washington State revealed that provider characteristics, including male gender and family practice specialty, predicted a lower adoption to CBE (13). In general, female primary health care providers in group practice settings were more likely to follow breast cancer screening guidelines (14). In Ontario, knowledge and practice gaps related to the implementation of the guideline recommendations for breast cancer management have been addressed within the primary care setting to improve the educational level of the providers through active interventions (21). Within the EMR, it has been reported that primary care providers, specifically the juniors, had low awareness, knowledge, and practices on breast cancer screening guidelines; stressing on the urgent need for postgraduate and continuous medical education (24-27).

Paramedical training is often directed to build capacities that are required to fulfill specific health-care roles, depending on the specialty, and is significantly less comprehensive than the sophisticated educational program requested for physicians. Earlier surveys from the United States have focused on the useful effective role of midlevel providers, including nurse practitioners and physician assistants, in cancer screening health promotion and disease prevention (22). Further studies emphasized on the implications for the educational needs of rural medical and paramedical health care providers regarding access to up-to-date cancer care information and guidelines for establishing effective referral linkages with the staff of the tertiary sector (23).

\section{Conclusions and Recommendations:}

In our country, women often rely on their primary health care providers to obtain adequate guidance on health promotion and screening. Our findings reveal insufficient conformity in the attitudes towards the practice of breast cancer management among the general paramedical providers in spite of their acceptable level of awareness. Capacity building of the paramedical staff, through directed interventions, is mandatory to ensure overcoming the existing barriers, abiding to protocol screening guidelines 


\section{International Journal of Science and Research (IJSR) \\ ISSN (Online): 2319-7064}

Index Copernicus Value (2015): 78.96 | Impact Factor (2015): 6.391

and adopting a successful nationwide public health educational program on breast cancer control in Iraq.

\section{Acknowledgement}

The authors thank Dr. RolaShaheen for her collaboration in designing the questionnaire utilized in the current study.

\section{References}

[1] Iraqi Cancer Board (2015). Results of the Iraqi Cancer Registry 2012. Baghdad, Iraqi Cancer Registry Center, Ministry of Health.

[2] Alwan NAS (2010). Breast cancer: demographic characteristics and clinico-pathological presentation of patients in Iraq. EMHJ; 16(11):1159-64.

[3] Alwan NAS (2016): Breast Cancer among Iraqi women: Preliminary Findings from a Regional Comparative Breast Cancer Research Project. Journal of Global Oncology, ASCO; 2 (1): 1-4.

[4] Von Karsa L, Qiao Y, Ramadas K, Keita N, Arrossi S, Boyle P, Alwan N \&Sankararanarayanan R (2014): World Cancer Report 2013. Implementation of Cancer Screening: The Global Outlook. IARC, WHO.

[5] Alwan N, Al-Attar W, Eliessa R, Al-Midfaei Z \&Nidhal F (2012):Knowledge, Attitude and Practice regarding Breast Cancer and Breast Self-Examination among a Sample of the Educated Population in Iraq. EMHJ, WHO, EMRO, 18 (4): 337-345.

[6] Alwan NAS, Al-Attar WM, Al Mallah N (2017): Baseline Needs Assessment for Breast Cancer Awareness among Patients in Iraq, International Journal of Science and Research (IJSR), Volume 6 Issue 1, $2088-2093$

[7] Al-Alwan N (2001): Colposcopy, Cervical Cytology and Human Papillomavirus Detection as Screening tools for Cervical Cancer". EMHJ, WHO, Eastern Mediterranean Regional Office, 7(1/2): 100-105.

[8] Alwan N, Al-Diwan J, Al-Attar W \&Eliessa R (2012): Knowledge, Attitudes and Practice towards Breast Cancer and BSE in Kirkuk University, Iraq. Asian Pacific Journal of Reproduction, Elsevier, 1 (4): 308311.

[9] Al Alwan N (2015): Establishing Guidelines for Early Detection of Breast Cancer in Iraq. Int. J. of Advanced Research. 3 (12): 539-555

[10] Sankar R, Alwan N \& Denny L (2013): "How Can We Improve Survival from Breast Cancer in Developing Countries?" Future Medicine, Breast Cancer Management, 2 (3): 179-183.

[11] Alwan N (2014): Iraqi Initiative of a Regional Comparative Breast Cancer Research Project in the Middle East, Journal of Cancer Biology \& Research, 2 (1): $1016-1020$.

[12] Wallace A.E., MacKenzie T.A., Weeks W.B. (2006): Women's primary care providers and breast cancer screening: Who's following the guidelines?. American Journal of Obstetrics and Gynecology, 194 (3) , pp. 744-748

[13] Desnick, L., Taplin, S., Taylor, V., Coole, D., and Urban, N (1999): Clinical breast examination in primary care: perceptions and predictors among three specialties. J Women's Health. 8: 389-397 112
[14] Pham, H.H., Schrag, D., Hargraves, J.L., Bach, P.B (2005): Delivery of preventive services to older adults by primary care physicians. JAMA. 294: 473-481

[15] Globocan 2012, International Agency for Research on Cancer, Lyon, IARC Press, 2013.

[16] Anderson BO, Yip CH, Smith RA, et al (2008): Guideline implementation for breast healthcare in low and middle-income countries: Overview of the Breast Health Global Initiative Global Summit 2007. Cancer 113(8): 2221-2243

[17]Annual Statistical Report 2015 (2016). Planning Directorate, Ministry of Health, Republic of Iraq.

[18] Miller T, Alwan N (2013): Concept note on screening and early detection of breast cancer in the Eastern Mediterranean Region. Regional Meeting on Cancer Control and Research Priorities, WHO/EMR. Doha, Qatar, October 22-24, 2013

[19] Alwan NAS and Al-Attar (2016): Evaluating the Effect of an Educational Teaching Model on the Knowledge about Breast Cancer among Female University Students in Iraq., JJ Cancer Sci. Res. 2(1): 026,

[20] Al Alwan NAS and Mualla FHM (2014). Promoting Clinical Breast Examination as a Screening Tool for Breast Cancer in Iraq. Iraqi National Journal for Nursing Specialities; 27 (1): 76-82

[21] Luctkar-Flude M, Aiken A, McColl MA, Tranmer J, Langley H (2015): Are primary care providers implementing evidence-based care for breast cancer survivors?. Can Fam Physician. Nov;61(11):978-84

[22] Alrudaini FA, Selim ME (2010): Breast Cancer Screening in Primary Health Care: Barriers and Predictors of Physicians' Adherence to Screening Guidelines Med. J. Cairo Univ. Vol. 78, No. 1, June: 303-309.

[23] Soliman A.S., Raouf A.A. and Chamberlain R.M (1997): Knowledge of, attitudes toward, and barriers to cancer control and screening among primary care physicians in Egypt: The need for postgraduate medical education. Journal of Cancer Education, 12 (2): 100107.

[24] Ghanem S, Glaoui M, Elkhoyaali S, Mesmoudi M, Boutayeb S, Errihani H (2011). Knowledge of risk factors, beliefs and practices of female healthcare professionals towards breast cancer, Morocco. Pan Afr Med J;10:21.

[25] Miller A (2015): Early Detection of Breast cancer in the Eastern Mediterranean Region: Practices and Lessons learned. WHO, EMRO.

[26] Reed CA, Selleck CS, ARNP, DSN (1996): The role of midlevel providers in cancer screening. Medical Clinics of North America. Vol. 80, Issue 1, Pages 135-144.

[27] Rayman KM, Edwards J (2010): Role in the Breast Cancer Care Continuum.. J of Rural Health, 26 (2): 189195.

\section{Author Profile}

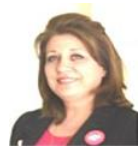

Prof.Dr. Nada A. S. Al Alwan(M.D. Ph.D.) is Professor of Pathology, Founding Director, National Cancer Research Centre, Baghdad University, Ministry of Higher Education \& Scientific Research, Iraq. She is Executive Director, Iraqi National Cancer Research Program and Chairperson, Medical Committee, Iraqi Scientific Research Council. She is Manager, Main Consultative Specialized

\section{Volume 6 Issue 7, July 2017 www.ijsr.net}




\section{International Journal of Science and Research (IJSR) \\ ISSN (Online): 2319-7064}

Index Copernicus Value (2015): 78.96 | Impact Factor (2015): 6.391

Clinic for Early Detection of Breast Tumours, Medical City

Teaching Hospital, Principal Investigator, Regional Comparative Breast Cancer Research Project, WHO / IARC. Currently, working as an Academic Visitor in Oxford University, UK, on a joint research comparing the demographic and clinico-pathological profiles of breast cancer among Iraqi and British patients. Prof. Nada Alwan organized the National Program for Early Detection and Down Staging of Breast Cancer in collaboration with the Iraqi $\mathrm{MoH}$ in 2001. Since then, specialized centres and clinics for early detection of breast cancer were established all over the Iraqi Governorates. In 2008, Prof. Alwan established the "Iraqi National Breast Cancer Research Program" chaired by the Ministry of Higher Education and Scientific Research. As an executive director of that national program, and following a visit to the Screening Unit of IARC (International Agency for Research on Cancer) in 2009, she developed, with their assistance, a comprehensive online information system data base for Iraqi patients complaining of breast cancer. In 2012, WHO/EMRO and IARC proposed utilizing that model to compare the demographic characteristics, clinicopathological presentations and management outcomes among patients affected with the disease in 8 countries within the Eastern Mediterranean Region through implementing a "Regional Comparative Breast Cancer Research Project". Within the fields of adopting national cancer control strategies and establishing early detection programs, Prof. Alwan served as an international expert and technical advisor to WHO/EMRO, IAEA, Technical Cooperation Program, US Middle East Partnership Initiative, Suzan G Komen for the Cure and the Jordan National Breast Cancer Program.

Volume 6 Issue 7, July 2017 www.ijsr.net 